\title{
Causes of Death in Patients with Aortic Aneurysmal Disease (1987-2014)
}

\author{
Raymond Englund \\ St. George Private Hospital, Kogarah, Australia \\ Email: renglund@ihug.com.au
}

How to cite this paper: Englund, R. (2017) Causes of Death in Patients with Aortic Aneurysmal Disease (1987-2014). Surgical Science, 8, 1-8.

http://dx.doi.org/10.4236/ss.2017.81001

Received: September 22, 2016

Accepted: January 9, 2017

Published: January 12, 2017

Copyright $\odot 2017$ by author and Scientific Research Publishing Inc. This work is licensed under the Creative Commons Attribution International License (CC BY 4.0).

http://creativecommons.org/licenses/by/4.0/ (c) (i) Open Access

\section{Abstract}

Introduction: This study examined the cause of death of patients with aortic aneurysms treated for this disease between 1987 and 2014 to understand the current natural history of this condition. Methods: This study results from analysis of a prospectively maintained data base of patients treated by the author. Data points were obtained from practice records and supplemented by data made available through CHeRL (Centre for electronic Health Record Linkage). Six hundred and twenty two patients were treated consecutively between 1987 and 2014. At closure of the study in 2014, 402 patients had died and date of death was available. Cause of death was available by ICD (International Classification of Diseases) 9 or 10 in $89 \%$ of patients. Method of treatment of aneurysmal disease was available in all patients. Ethics approval for this study was obtained from the Centre for Health Research, Cancer Institute, New South Wales Department of Health. Statistical analysis was conducted by comparison of mean $\pm 95 \%$ conference interval. Where appropriate contingency table analysis was constructed. Statistical significance was accepted at $\mathrm{P}$ $<0.05$. Results: Mean age at presentation was 75.6 years (95\%C.I. $74.8-76.3$ ). Mean age at death was 81 years (95\%C.I. 80.2 - 81.7). Predicted age at death based on Australian Bureau of Statistics life tables was 86.25 years (95\%C.I. 85.8 - 86.8). Between 1987 and 1999, mean age at presentation was 74.5 years (95\%C.I. $73.3-75, \mathrm{n}=304$, Females $=78$ ). Between 2000 and 2014, mean age at presentation was 75.3 years (95\%C.I. $74.1-75, \mathrm{n}=318$, females $=54)$. The difference for females presenting 1987 to 1999 compared 2000 to 2014 was significant, $p<0.01$. Death was due to the following causes unknown $11 \%$, cardiovascular disease $27.7 \%$, pulmonary related disease $9.7 \%$ and aortic related disease $20.6 \%$. Patients died of aortic related causes significantly earlier (within 2 years) compared to patients with other causes of death (5 to 8 years) due to presentation with ruptured aortic aneurysm. Cardiovascular related causes of death, malignancy and pulmonary related causes of death accounted for the majority of deaths post-treatment. There was no significant difference in length of survival among patients dying from these causes. Conclusion: Patients with successfully treated aneurysmal disease can expect to survive 5 - 8 years posttreatment. Presentation with aortic aneurysm rupture results in significantly short- 
ened life expectancy. Patients presenting in the ninth decade of life and with less than 5 years life expectancy may not benefit from elective repair of aortic aneurysm.

\section{Keywords}

Cause of Death, Aortic Aneurysm, Survival, Long Term

\section{Introduction}

When cause of death is considered in relation to patients with aortic aneurysm disease, the focus has been on preventing death from ruptured aneurysm [1] [2]. Following the report of DuBost and Oeconomos [3] on successful repair of aortic aneurysms, the natural history of aortic aneurysmal disease changed fundamentally. Since then, the understanding of the natural history of aortic aneurysm disease has been defined only in patients who have aortic aneurysmal disease but are unfit for surgical repair [4]. In 1997, the author reported a study entitled "outcome for patients with abdominal aortic aneurysms that are treated non-surgically" [5]. In this study, we found that patients who were unfit for surgery most frequently died as a result of the condition that makes the patient unfit for surgical repair. The EVAR 2 Trial [6] demonstrated that those patients who are unfit for open surgical repair do not benefit from Endovascular Aneurysm Repair (EVAR).

In this study, we have examined all patients who have been treated for aortic aneurysmal disease by the current standards of practice. The objective of this study was to assess the natural history of patients with aortic aneurysm disease in the light of modern clinical practice. The information produced from this study could be used to aid management of elderly patients with aortic aneurysm disease.

\section{Methods}

The patients in this study are all those treated by the principal author for aortic aneurysm disease between 1987 and 2014. A prospectively created practice based data record was maintained during this period. All patients were followed postoperatively at 12 monthly intervals. If treated conservatively, patients were also seen annually. On each occasion of follow up an ultrasound examination of the aorta was conducted. Thoracic reconstructions were followed as required by CT scanning.

Follow up data was complemented where appropriate by information obtained from the Centre for Health Record Linkage (CHEREL) and from the Registry of Birth Deaths and Marriages, New South Wales Government. The Centre for population Health and Research, Department of Health New South Wales provided ethics approval under the title HREC/14/CIPHS/44 Cancer Institute of New South Wales reference number 2014/07/542. Project title: Single practice review of treated aortic aneurysms 1980 7/2/2014 [7].

Data end points selected for this study were age and sex at presentation or initial treatment, date of presentation or treatment, type of treatment, date of death, and cause of death as classified by ICD (International Classification of Disease) 9 and 10. 
Initial analysis involved an assessment of age and sex of all patients at presentation to determine whether or not there had been a variation in these parameters at yearly intervals over the course of the study. Additionally the study was divided into 2 periods, 1987 to1999 and 2000 to 2014 . The patient groups for these periods were compared.

Patients who were known to have died between 1987 and 2014 were then studied with respect to type of treatment of aneurysm disease, duration of survival post treatment and identified cause of death. Date of death was available for all patients in this study.

In some patients cause of death was not known and these patient's were classified as unknown cause of death. When cause of death was provided by ICD 9 or 10 code, the cause of death was classified into one of the following categories, cardiovascular disease, aortic related cause, malignancy, pulmonary-related disease, gastrointestinal related cause, chronic renal failure, sepsis, senility, drug related cause, paraplegia, diabetes related cause, dyslipidaemia and cause related to connective tissue disease.

Cross tabulation of these categories with the following treatment type was performed, open abdominal aortic reconstruction, open thoracic aortic reconstruction, endovascular aortic aneurysm repair (abdominal) (EVAR), open repair for ruptured aortic aneurysm, thoracic endovascular repair (TEVAR), no operation with elective follow up and no operation presenting with ruptured aortic aneurysm.

Where appropriate for the purpose of comparing means, 95\% confidence intervals were calculated to compare groups and variation between groups. Contingency tables were analysed by Chi squared test and significance accepted at $\mathrm{p}<0.05$ level.

\section{Results}

Examination of the age at presentation classified by year of presentation is shown in Figure 1. The mean age at presentation is given by year of presentation with $95 \%$ confidence intervals. The age of presentation was constant during this study. Presentation was almost invariably in eighth decade of life and most frequently during the first half of this decade. Over the period 1987 to 2014 of this study there was no variation in age at time of presentation. For the first period, 1987-1999 the mean age was 74.2 years ( $95 \%$ CI: $73.3-75, \mathrm{n}=304$ ). In the second period, 2000 to 2014 mean age 75.3 years (95\% CI: $74.1-76.2, \mathrm{n}=318$ ).

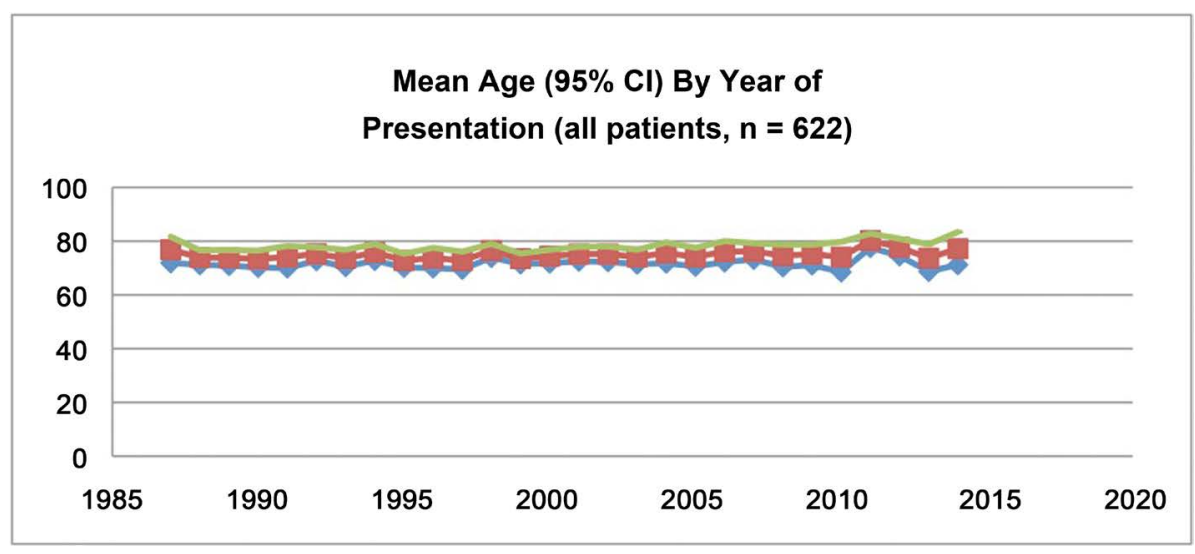

Figure 1. Mean age by year of presentation. 
Between 1987 and 1999, 25\% ( $\mathrm{n}=78)$ of patients were female while 17.3\% $(\mathrm{n}=54)$ were female in the period 2000 to 2014. Contingency table analysis, Chi-squared $=6.9$, $1^{\circ}$ of freedom, $\mathrm{P}<0.01$. Therefore female patients presented less frequently during the second period 2000to 2014.

There were 402 patients from total of 622 patients who were deceased at the time of completion of the study in 2014. In all 402 patients date of death was available. The cause of death was not determined in 46 patients (11\%). Cause of death is cross tabulated with type of treatment in Table 1 . The most common cause of death was due to cardiovascular disease (27.6\%). The second most frequent cause of death was aortic related $(20.6 \%)$. In the majority of these cases death was related to presentation with a ruptured aortic aneurysm with operation $(n=35)$ or with ruptured aortic aneurysm treated conservatively $(n=25)$. The remaining patients presented at later dates with aneurysms in the thoracic or iliac segments or developed complications such as aorto-enteric fistula or graft infection. Causes of death other than aortic related death accounted for $80 \%$ of mortality. Table 1 cross references duration of survival with cause of death for the 8 most frequent causes of death. Among causes of death, with the exception of aortic related death, duration of survival post presentation or treatment was consistently between 5 - 8 years and did not significantly vary. Aortic related death resulted in significantly shorter survival than all others. This is mostly due to presentation with ruptured aortic aneurysms.

Gender distribution between the most frequent causes of death showed no significant difference between cause of death and expected frequency of males and females within

Table 1. AAA deaths.

\begin{tabular}{|c|c|c|c|c|c|c|c|c|c|c|c|c|c|}
\hline 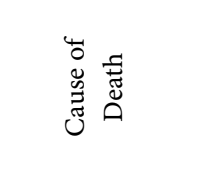 & 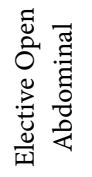 & $\sum_{\text {省 }}$ & $\begin{array}{l}\dot{0} \\
\sum_{\tilde{0}} \\
\tilde{0}\end{array}$ & 蛋 & 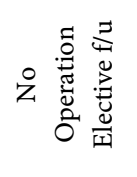 & $\begin{array}{l}\dot{2} \\
\dot{2} \\
\dot{z}\end{array}$ & $\partial^{\circ}$ & 总 & 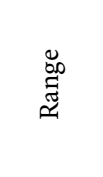 & $\sum_{\Sigma}^{\frac{0}{\pi}}$ & 褐 & 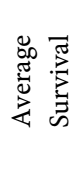 & 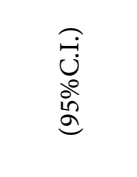 \\
\hline $\mathrm{CVS}^{*}$ & 60 & 19 & 12 & 5 & 18 & 0 & $115(27.6 \%)$ & 75.16 & $53-93$ & 84 & 31 & 6.27 & $5.3-7.2$ \\
\hline Aortic related & 29 & 3 & 24 & 1 & 10 & 15 & $83(20.6 \%)$ & 77.89 & $56-95$ & 60 & 23 & 2.2 & $1.2-3.23$ \\
\hline Malignancy & 35 & 9 & 7 & 3 & 10 & 0 & $64(16 \%)$ & 74.8 & $58-88$ & 55 & 9 & 5.5 & $4.6-6.4$ \\
\hline Unknown cause & 20 & 15 & 0 & 1 & 9 & 0 & $46(11.4 \%)$ & 75.2 & $61-88$ & 32 & 14 & 6.9 & $5.4-8.3$ \\
\hline Pulmonary & 14 & 9 & 11 & 1 & 4 & 0 & $39(9.7 \%)$ & 75.5 & $63-89$ & 34 & 5 & 6.75 & $6.57-6.94$ \\
\hline G.I.** & 8 & 2 & 5 & 0 & 3 & 0 & $18(4.6 \%)$ & 76.7 & $65-94$ & 15 & 3 & 6.6 & $4.6-8.6$ \\
\hline $\mathrm{CRF}^{* * *}$ & 8 & 3 & 0 & 0 & 0 & 0 & $11(2.7 \%)$ & 71.2 & $55-82$ & 8 & 3 & 8.4 & $5.6-11.2$ \\
\hline Sepsis & 3 & 1 & 4 & 0 & 0 & 0 & $8(1.9 \%)$ & 77.5 & $69-89$ & 6 & 2 & 7.18 & $3.3-11$ \\
\hline Senility & 1 & 1 & 1 & 0 & 1 & 0 & $4(1 \%)$ & 75.5 & $61-86$ & 3 & 1 & & \\
\hline Drug related & 1 & 2 & 0 & 0 & 1 & 0 & $4(1 \%)$ & 79 & $69-89$ & 3 & 1 & & \\
\hline Paraplegia & 1 & 1 & 0 & 0 & 0 & 0 & $4(1 \%)$ & 74 & $60-85$ & 3 & 1 & & \\
\hline Diabetes & 1 & 0 & 1 & 0 & 0 & 0 & $2(0.5 \%)$ & 84 & $84-85$ & 2 & 0 & & \\
\hline Dyslipidaemia & 0 & 1 & 1 & 0 & 0 & 0 & $2(0.5 \%)$ & 75 & $73-78$ & 1 & 1 & & \\
\hline $\begin{array}{l}\text { Connective } \\
\text { tissue }\end{array}$ & 1 & 0 & 1 & 0 & 0 & 0 & $2(0.5 \%)$ & 75 & $72-78$ & 2 & 0 & & \\
\hline Total & 182 & 66 & 67 & 11 & 56 & 15 & $402(100 \%)$ & & & 308 & 94 & & \\
\hline
\end{tabular}

${ }^{\star}$ Cardiovascular system related deaths; ${ }^{* *}$ Gastrointestinal; ${ }^{* *}$ Chronic renal failure. 
each of the 8 categories (Chi-squared $=10.1,7^{\circ}$ of freedom, $\mathrm{p}>0.05$ ).

For the total of 402 patients with known date of death, average age at presentation was 75.6 years (95\% CI: 74.8 - 76.3). Age at death was 81 years (95\% CI: 80.2 - 81.77). Predicted age and survival based on Australian Bureau of statistics life tables was 86.25 years (95\% CI: 85.8 - 86.88) and 10.62 years (95\% CI: 10.2 - 11). Presence of aortic aneurysm disease conferred a significantly shortened life expectancy compared to predicted population survival.

\section{Discussion}

In this study between 1987 and 2014 there was very little variation in the age of presentation among patients with aortic aneurysmal disease. Aneurysmal disease of the aorta remained a disease of the eighth decade of life most frequently presenting in the first half of this decade.

Female gender presentation accounted for 25\% of patients between 1987 and 1999 but only $17.5 \%$ in the period between 2000 and 2014. This was a significant decrease during that period and may have been related to the decrease in prevalence of smoking among females and those over 55 years of age during that period [8].

Patients with aortic aneurysmal disease in this study had an incidence of $20 \%$ of death from aortic related disease. In the majority of cases this death was related to presentation with ruptured aortic aneurysm. The majority who died did so following operation but a significant part of this group also consisted patients whose quality of life and fitness for operation did not warrant intervention. Additionally there was a small group who refused elective intervention but later presented with rupture resulting in death.

Cardiovascular disease (28.6\%) and pulmonary disease (9.7\%) accounted for almost $40 \%$ of deaths. Death due to malignancy made a significant contribution to mortality. The total of $80 \%$ of deaths in this study was related to cause other than those pertaining to disease of the aorta.

Duration of survival in the aortic related group was significantly less than the duration of all other groups. The majority of patients dying from aortic related causes were dead within 2 years. Once again this is most likely due to those patients presenting with ruptured aortic aneurysm. Those dying with a longer delay did so as a result of graft sepsis and intestinal erosion or recurrent aneurysmal disease at other sites.

In general the overall survival among different groups as classified by cause of death was relatively consistent. The majority of patients not dying from aortic related death did so within 5 - 8 years post presentation.

In 1972 Szilagyi et al. reported on the clinical course of 156 patients who were considered unfit for surgery between 1952 and 1977. One hundred and twenty seven of these never came to operation and 90 died during the 20 year follow up. Cardiovascular disease accounted for death in 55\% but aortic aneurysm rupture resulted in death in $27.8 \%$. Similarly in 1975 Thompson et al [9], reporting on an experience with elective aneurysm repair reported a 5.5\% mortality rate post operation and attributed all these deaths to either cardiac or pulmonary causes. Stanley-Crawford et al. [10] in 1981 reported on 191 patients with complete survival information analysed by life table tech- 
nique over 15 years. They found a significant relationship between long-term survival and the presence or absence of heart disease or hypertension. Hollier et al. [11] reported an increasing incidence of aortic aneurysm disease, a significant disparity between age of women and men presenting with aortic aneurysms and a significant relationship between diameter of aneurysms and presentation with rupture. They used this patient group to demonstrate that advanced age and heart disease or hypertension significantly effected long-term survival [12]. Contrary to this Wayne-Johnston and Scobie [13] in a multi centre prospective study found that preoperative correction of coronary artery disease by operation did not improve operative mortality rate although they later identified cardiovascular disease as a significant contributor to mortality. In a followup report of this patient group in 1994 [14] cardiovascular disease and advanced age were found to be significant contributors to long-term mortality. The role of cardiovascular disease in mortality was again demonstrated by study in 1997 Sayers et al. [15]. In 1998 the UK Small Aneurysm Trial [16] highlighted the importance of size with respect to risk from rupture. This study demonstrated that aneurysms smaller than 5.5 $\mathrm{cm}$ in diameter could be safely followed with ultrasound surveillance. Conway et al. [17] in response to the UK Small Aneurysm Study examined patients $(\mathrm{n}=106)$ with aneurysms greater than $5.5 \mathrm{~cm}$ in diameter and considered unfit for surgery. They found a progressive relationship between increasing aortic aneurysm diameter and death from ruptured aneurysm. A similar study reported by Lederle et al. [18] unsurprisingly found similar results. They made the statement "these diameters could serve as useful thresholds for decision making... but may not apply to women."

The EVAR 2 Trial purported to compare patients unfit for open repair treated conservatively $(n=172)$ and patient's unfit for open repair treated by endovascular aneurysm repair EVAR $(n=166)$. Although patients were randomised into either of these 2 groups, 192 patients underwent aneurysm repair. There appeared to be some crossover between the groups and a significant number of patients assigned to no intervention underwent open repair. Based on these parameters it is hard to believe that the EVAR 2 trial is the definitive answer to the treatment of patients unfit for open repair of aortic aneurysm. However the authors claimed to have demonstrated no benefit for either in this patient group.

In current practice a clinician may be faced with the decision as to what recommendation to make to a patient as an appropriate management strategy. The question arises as to how one can arrive at a rational decision based on current data. Clearly not every patient with an aortic aneurysm will die from an aortic related disease such as rupture. EVAR appears to carry a reduced risk of peri-operative death [19]. Patients could reasonably be excluded for consideration for intervention for the following reasons quality of life considerations, presence of short-term terminal illness or condition, small aneurysm under 5 - $5.5 \mathrm{~cm}$ diameter, patient rejection of intervention. For patients remaining the following considerations could be made; age and sex of patient, size of aortic aneurysm, surgeon's mortality rate and any intercurrent conditions which may influence mortality rate such as chronic renal failure (if EVAR is contemplated) or significant cardiovascular disease and intercurrent drugs that may need to be ceased for the procedure thus posing a risk in relationship to their cessation. 
For patients 80 years or more, in this study we found that $95 \%$ of patients died within 2 years of presentation therefore time benefit for these patients may be no more than 2 years.

Consideration of aneurysm size may be the next most important issue. Lederle et al. found probable risks of rupture with initial aneurysm diameter $6.5 \mathrm{~cm}$ to $6.9 \mathrm{~cm}$ was $10.3 \%$ at 6 months, $19.1 \%$ at 12 months and $19.1 \%$ at 18 months. One would probably need to take into consideration that these diameters may not be appropriate for females and adjust accordingly [18].

For males of 80 years of age and aortic aneurysm greater than $5.5 \mathrm{~cm}$ in diameter with no intercurrent medical conditions in the hands of the Surgeon with standard mortality rate it would seem reasonable to offer either open or EVAR procedures. For males with concurrent coronary artery disease taking an anticoagulant or antiplatelet inhibitor, EVAR may be preferred over open operation. In the presence of significant renal impairment but not dialysis dependent renal failure, EVAR may be contraindicated. In short successful treatment of aortic aneurysm disease and long-term benefit is predicated on selection of patients for an appropriate procedure. Reasonable risk assessment predicated on known factors is likely to influence both short and long-term survival.

\section{Conclusion}

Aortic aneurismal disease is a degenerative condition most commonly presenting in the eighth decade of life and affecting mainly males. Successful modern treatment confers an extra 5 to 8 years life expectancy. Death from disease of the aorta accounts for $20 \%$ of deaths while $80 \%$ of patients die from degenerative disease of other organ systems. Overall aortic aneurismal disease represents a marker for systemic degenerative disease.

\section{References}

[1] Szilagyi, D.E., Smith, R.F., De Russo, F.J., Elliott, J.H.P. and Sherrin, F.W. (1966) Contribution of Abdominal Aortic Aneurysmectomy to Prolongation of Life. Annals of Surgery, 164, 678. https://doi.org/10.1097/00000658-196610000-00014

[2] Szilagyi, D. (1972) Clinical Fate of the Patient with Asymptomatic Abdominal Aortic Aneurysm and Unfit for Surgical Treatment. Archives of Surgery, 104, 600. https://doi.org/10.1001/archsurg.1972.04180040214036

[3] Dubost, C., Allary, M. and Oeconomos, N. (1952) Resection of an Aneurysm of the Abdominal Aorta: Reestablishment of the Continuity by a Preserved Human Arterial Graft, with Result after Five Months. Archives of Surgery, 64, 405.

[4] Søreide, O., Grimsgaard, C., Myhre, H., Solheim, K. and Trippestad, A. (1982) Time and Cause of Death for 301 Patients Operated on for Abdominal Aortic Aneurysms. Age and Ageing, 11, 256-260. https://doi.org/10.1093/ageing/11.4.256

[5] Englund, R., Perera, D. and Hanel, K. (1997) Outcome for Patients with Abdominal Aortic Aneurysms That Are Treated Non-Surgically. ANZ Journal of Surgery, 67, 260-263. https://doi.org/10.1111/j.1445-2197.1997.tb01959.x

[6] EVAR Trial Participants (2005) Endovascular Aneurysm Repair and Outcome in Patients Unfit for Open Repair of Abdominal Aortic Aneurysm (EVAR Trial 2): Randomized Controlled Trial. ACC Current Journal Review, 14, 53-54. https://doi.org/10.1016/j.accreview.2005.09.089 
[7] HRCE/14/ciphs/44: Cancer Institute of NSW. Reference Number: 2014/07/542. Project Title: Single Practice Review of Treated Aortic Aneurysms, 1987-2014.

[8] Tobacco Smoking Australian Health Survey, 2011-2012. AIHW, ABS.

[9] Thompson, J.E., et al. (1975) Surgical Management of Abdominal Aortic Aneurysms: Factors Influencing Mortality and Morbidity-A 20-Year Experience. Annals of Surgery, 181, 654.

[10] Crawford, E.S., et al. (1981) Infrarenal Abdominal Aortic Aneurysm: Factors Influencing Survival after Operation Performed Over a 25-Year Period. Annals of Surgery, 193, 699.

[11] Bickerstaff, L.K., et al. (1984) Abdominal Aortic Aneurysms: The Changing Natural History. Journal of Vascular Surgery, 1, 6-12. https://doi.org/10.1016/0741-5214(84)90178-2

[12] Hollier, L.H., et al. (1984) Late Survival after Abdominal Aortic Aneurysm Repair: Influence of Coronary Artery Disease. Journal of Vascular Surgery, 1, 290-299. https://doi.org/10.1016/0741-5214(84)90060-0

[13] Johnston, K.W. (1989) Multicenter Prospective Study of Nonruptured Abdominal Aortic Aneurysm. Part II. Variables Predicting Morbidity and Mortality. Journal of Vascular Surgery, 9, 437-447. https://doi.org/10.1016/S0741-5214(89)70007-0

[14] Johnston, K.W. and Scobie, T.K. (1988) Multicenter Prospective Study of Nonruptured Abdominal Aortic Aneurysms. I. Population and Operative Management. Journal of Vascular Surgery, 7, 69-81. https://doi.org/10.1016/0741-5214(88)90380-1

[15] Sayers, R.D., et al. (1997) Surgical Management of 671 Abdominal Aortic Aneurysms: A 13 Year Review from a Single Centre. European Journal of Vascular and Endovascular Surgery, 13, 322-327. https://doi.org/10.1016/S1078-5884(97)80105-0

[16] (1998) Mortality Results for Randomised Controlled Trial of Early Elective Surgery or U1trasonographic Surveillance for Small Abdominal Aortic Aneurysms. The Lancet, 352, 16491655.

[17] Conway, K.P., et al. (2001) Prognosis of Patients Turned down for Conventional Abdominal Aortic Aneurysm Repair in the Endovascular and Sonographic Era: Szilagyi Revisited. Journal of Vascular Surgery, 33, 752-757. https://doi.org/10.1067/mva.2001.112800

[18] Lederle, F.A., et al. (2002) Rupture Rate of Large Abdominal Aortic Aneurysms in Patients Refusing or Unfit for Elective Repair. JAMA, 287, 2968-2972. https://doi.org/10.1001/jama.287.22.2968

[19] Greenhalgh, R.M. and The EVAR Trial Participants (2004) Comparison of Endovascular Aneurysm Repair with Open Repair in Patients with Abdominal Aortic Aneurysm (EVAR Trial 1), 30-Day Operative Mortality Results: Randomised Controlled Trial. The Lancet, 364, 843-848. https://doi.org/10.1016/S0140-6736(04)16979-1 
Submit or recommend next manuscript to SCIRP and we will provide best service for you:

Accepting pre-submission inquiries through Email, Facebook, LinkedIn, Twitter, etc. A wide selection of journals (inclusive of 9 subjects, more than 200 journals) Providing 24-hour high-quality service

User-friendly online submission system

Fair and swift peer-review system

Efficient typesetting and proofreading procedure

Display of the result of downloads and visits, as well as the number of cited articles Maximum dissemination of your research work

Submit your manuscript at: http://papersubmission.scirp.org/

Orcontact ss@scirp.org 